\title{
De "matrero" a símbolo nacional: la imagen literaria del gaucho en dos novelas argentinas del siglo XIX
}

\author{
Eugenia ORTIZ GAMBETTA \\ Universidad de Montevideo-Agencia Nacional de Investigación e Innovación del Uruguay
}

\begin{abstract}
RESUMEN
Este artículo tiene como objetivo principal estudiar la representación literaria del gaucho en dos novelas de la Organización Nacional argentina: Aventuras de un centauro en la América Meridional (1868), de José J. de Vedia, y Pablo o la vida en las pampas (1869-70), de Eduarda Mansilla. En primer lugar, se dará un contexto sobre la narrativa de tema gauchesco, los antecedentes y las influencias de las novelas elegidas. En segundo lugar, se desarrollará la elaboración del tipo "gaucho malo" (Sarmiento) en la diégesis de cada obra. Por último, se verá cómo en las prosopografías y las etopeyas se representa la dinámica de la transformación de un individuo marginal en un modelo cultural idealizado.
\end{abstract}

Palabras claves: novela de gauchos, Eduarda Mansilla, José J. de Vedia, intertextualidad, imagen literaria.

From "matrero" to a national symbol: gaucho literarian image in two XIXth argentine novels

\begin{abstract}
The aim of this paper is to analyze the gaucho's literarian representation in two argentinian novels of the Organización Nacional: José J. de Vedia's Aventuras de un centauro en la América Meridional (1868) and Eduarda Mansilla's Pablo o la vida en las pampas (1869-70). In the first place, a context of the narrative of the gaucho subject is presented, along with the backgrounds and influences of the chosen romans. In second place, the elaboration of the "gaucho malo" prototype (Sarmiento) in the diegenesis of each work is developed. At last, an analisis of the prosopographies and the etopeyas represents the dynamics of the transformations of marginal individuals into an idealiced cultural model.
\end{abstract}

Key words: Gaucho novels, Eduarda Mansilla, José J. de Vedia, intertextuality, literary image. 
Antes de la primera publicación del Martín Fierro (1872), el gaucho tuvo su representación literaria no sólo en la poesía, sino también en el género novelístico ${ }^{1}$. Durante los años de la Organización Nacional en Argentina (1852-1880) se acentuó el proceso de militarización del hombre de la campaña, lo que trajo como consecuencia la denominación del paisano que se rehusaba a alistarse como "matrero" o "fugitivo". La huida permanente, el contacto y negocio con el indio, y su condición de individuo fronterizo convirtieron al gaucho en un habitante digno de la atención de viajeros y de escritores locales, pero también de la nueva dirigencia política que los tomaban como "vagos y malentretenidos".

Las campañas de homogeneización de la población argentina, que se encarnaron en discursos políticos y novelísticos donde el europeo mejoraba o blanqueaba la raza criolla, consideraban al gaucho como un atentado porque su condición de outlaw remarcaba la hibridez étnica y la barbarie despreciada. Sin embargo, la buscada mimesis de los proyectos culturales de la primera generación literaria argentina se encarnó -clara paradoja- en el factor más rechazado.

En 1868, José Joaquín de Vedia publicó en Buenos Aires Aventuras de un centauro de la América Meridional, el mismo año en el que Eduarda Mansilla terminó de escribir en francés su novela Pablo, o la vida en las pampas, publicada en Francia como folletín y libro en 1869. Ambas novelas sobre gauchos fueron precursoras en su tipo. Por un lado, porque precedieron a Juan Cuello, historia de un argentino de Manuel Olascoaga, a los populares folletines de Eduardo Gutiérrez y a una larga lista de hitos literarios del siglo XX, como los relatos de Güiraldes y Lynch; y, por el otro, porque el tema central de estas novelas es la denuncia del maltrato y la desidia del gobierno con respecto a los gauchos, un asunto que siempre se atribuyó como innovación a los artículos periodísticos de José Hernández y a su Martín Fierro.

El primer antecedente del tema en narrativa fue, sin duda, Facundo, bajo la sombra del cual se recrearon muchos tipos gauchescos, pero la introducción del gaucho en la novela le pertenece a Caramurú, del uruguayo Alejandro Magariños Cervantes. Aunque esta obra desarrolla la historia de un gaucho matrero, leyenda y héroe popular, el narrador no explica las condiciones socio-políticas que propiciaron el surgimiento de este fenómeno social. Caramurú/Amaro es el jefe de una montonera a favor de la independencia de la Banda Oriental y el contexto de la

${ }^{1}$ A partir de mi estudio sobre la novela argentina de la Organización Nacional (Ortiz, 2013), he delimitado un corpus de novelas de gauchos. Estas obras son: Caramurú, de Alejandro Magariños Cervantes (publicada en Madrid en 1851 y en Buenos Aires, en 1865), El bandido de X (seudónimo de autor no identificado) de 1866, Aventuras de un centauro de la América Meridional, de José Joaquín de Vedia (1868) y Pablo, ou La vie dans les Pampas (1869) de Eduarda Mansilla, cuya segunda edición es una traducción de Lucio Mansilla, Pablo, o la vida en las pampas, de 1870. Las obras que trabajo en este artículo no son incluidas en el profundo trabajo de Schlickers (2007) sobre el género gauchesco. 
guerra justifica sus acciones. Además, lo central en esta obra no son las aventuras del gaucho, sino su relación con Lía Niser, hija de un rico montevideano y prometida de un conde brasileño, por lo que la obra tiene una estructura propia de una novela sentimental.

A pesar de esto, en el relato de Magariños hay una presencia de elementos que serían recurrentes en posteriores obras literarias sobre el asunto porque, por ejemplo, Amaro tiene las características de quien Sarmiento describe como "gaucho malo" (Magariños Cervantes, 1865: 16-22) y en su argumento no faltan la pendencia en la pulpería (11-19), el trato con los indígenas (89) y la afición a juegos como las carreras (149-159). Es también interesante el tratamiento del lenguaje en la novela, ya que el narrador introduce palabras propia de paisanos, y va aclarando en nota al pie su significado, hasta que deja de hacerlo, no sin antes apuntar que no utilizará toda la jerga de los gauchos porque necesitaría interrumpirse a cada paso para explicarla (13). De todos modos, hay una intención de imitar el lenguaje rural la mayor cantidad de veces posibles, sobre todo en los diálogos.

Caramurú es un verdadero antecedente literario de Pablo... y Aventuras..., porque hace un interesante aporte a la figura literaria del gaucho. Sin embargo, aun conociendo las circunstancias de este individuo en las campañas rioplatenses, Magariños Cervantes no tiene intenciones de hacer una arenga a favor de este grupo social en su obra. Aunque no pudiera clasificarlo como hipotexto, hay relaciones intertextuales entre estas tres obras. Todas recrean las peripecias de dos gauchos que se escapan del servicio militar al que los obligan los respectivos gobiernos de turno ${ }^{2}$.

Pablo, o la vida en las pampas y Aventuras de un centauro son dos obras que podrían haberse escrito en el mismo ambiente, bajo el efecto de idénticas experiencias o conversaciones pero, a pesar de los puntos argumentales que comparten, el origen de cada relato es diferente. Por un lado, Pablo... se publicó como folletín en la revista parisina L'Artiste, de Arsene Houssaye, y fue publicada como libro en 1869 por la editorial de E. Lachaud. La primera edición en español, cuya traducción estuvo a cargo del hermano de la autora, Lucio V. Mansilla, fue realizada por entregas en el periódico La Tribuna, entre el 28 de noviembre y el 30 de diciembre de 1870 .

La edición francesa de la novela de Mansilla incluye un verdadero glosario de términos en español y su explicación, como "papeleta", "tacuara", "mate", "payador", "pago" o "pulpería", y también notas sobre el significado de alguna

${ }^{2}$ Hay algunos datos que podrían confirmar que tanto Mansilla como Vedia leyeron Caramurú. Por ejemplo, hay muchas acciones similares en Aventuras... y en la obra de Magariños Cervantes, como el rapto de la mujer, la lucha con un «león» en el desierto — que también aparece en Facundo, cuando Quiroga se enfrenta con un tigre (Sarmiento, 1990: 128-130)—, y la amistad con los caciques (en el caso de Aventuras ..., con Catriel). 
frase, como el de la expresión "ser judío", o la definición de elementos de la flora y fauna local. Además, hay muchas palabras, interjecciones o inicios de frases en los diálogos, que la autora deja en español y no consigna a pie de página. En total, el texto original incluye cuarenta y cinco definiciones o explicaciones de términos y frases. La traducción de Lucio deja huellas del original, por ejemplo, en los deícticos del discurso ("allí", "aquí", "nosotros"), y en las explicaciones de las costumbres argentinas (Mansilla, 2007: 110, 171, 232, 231) o de la situación sociopolítica, dirigidas al lector europeo (pp. 113; 115). Estos indicadores del público original recuerdan, a su vez, el punto de vista de un relato de viajes aunque, al revés de lo que sucede en el género - y al estilo de Facundo - , la autora es oriunda de la tierra que describe.

En la novela de Eduarda Mansilla, los gauchos e indios "no se parecen a los de Echeverría, llegan primero que los de José Hernández y acaso presienten los de su hermano Lucio" (Mizraje, 2007: 40). También sucede otro tanto con Aventuras..., donde el narrador introduce estos mismos elementos y ciertos personajes que ya habían sido descritos por Sarmiento en Facundo.

El "gaucho malo" aparece en las dos, lo mismo que el "gaucho cantor" o payador, ya que Pablo y Bruno el Campeador eran famosos por sus versos y su virtud con la guitarra (Vedia, 1868: 72-73). La influencia de esta obra es más notable, sin embargo, en Pablo... que en Aventuras ..., tal como lo han consignado varios críticos $^{3}$. No sólo están presentes las antes citadas tipologías, sino también la del baqueano, aquel que en Pablo... es capaz de reconocer la propiedad con sólo probar la tierra (Mansilla, 2007: 208) — habilidad que, según Sarmiento [1990: 86], también tenía Juan Manuel de Rosas-, y otras alusiones, como la del quechua hablado en la provincia de Santiago del Estero (Mansilla, 2007: 229), también comentado en Facundo (Sarmiento, 1990: 63), al igual que la descripción de la pampa como un mar (Mansilla, 2007: 98-99). A diferencia de lo que sucedería con Martín Fierro y los folletines de Eduardo Gutiérrez, la novela de tema rural de Mansilla estuvo dirigida, tanto en el ámbito europeo (y norteamericano) como en el argentino, a un público culto de ciudad.

Es difícil, por su parte, rastrear los avatares de la edición de Aventuras..., así como recabar datos de la vida del autor. Esta obra presenta ciertas particularidades, sobre todo con lo que respecta a su género discursivo. Aunque no es un relato muy cuidado, la vida del gaucho está bien presentada; sin embargo, la narración está salpicada de párrafos ensayísticos que el narrador denomina "digresiones" (Vedia, 1868: 115), y cuya frecuencia puede obstaculizar la lectura. Además, el relato tiene visos de narración oral transcrita, porque el enunciador hace referencia a lo que está sucediéndole en el mismo momento de la escritura, como cuando comenta un hecho político acontecido ese mismo día (197), o un timbre que suena en ese instante

\footnotetext{
${ }^{3}$ Entre ellos, Masiello (1997), Batticuore (2005) y Mizraje (2007).
} 
(112) o cuando consigna que Bartolomé Mitre se sonrió, después de leer un pasaje del texto (100); incluso, hace mención del mal humor que tiene mientras escribe (114).

Las referencias internas del texto sobre su género son contradictorias. Por un lado, el narrador asegura que su obra no es de imaginación y que, además, citará fechas "según el entender de algunos romancistas" (4), ya que lo importante de su relato es el interés histórico. Por momentos, llama a su trabajo "apuntes semihistóricos" (23), y por otro, alude a que "los historiadores no querrán que nos invistamos con sus atribuciones" (170). De todas formas, menciona como fecha de los sucesos la década de 1820, y los diálogos y las aventuras son escritos, por lo general, con un estilo muy cercano a la narración novelística de la época. La fluctuación genérica y los excursus histórico-sociológicas del autor no desestructuran las aventuras, y las referencias constantes al Quijote no hacen más que confirmar la preeminencia de lo novelístico en el relato.

Williams Alzaga (1955: 135) y Chumbita (2000: 29) sostienen que Vedia se basó en la leyenda popular de Juan Cuello para elaborar su obra, pero no hay modo de contrastarlo más que considerando la novela de Eduardo Gutiérrez. De este modo, se comprueba que entre estas dos versiones hay muchas diferencias, empezando por que el personaje no vive en Buenos Aires sino en la campaña, y su nombre no es Juan Cuello, sino Irene Campoamor. De todos modos, en la novela de Vedia hay marcas textuales que revelan que la historia contada en Aventuras... es la plasmación de un relato oral (Vedia, 1868: 5, 12) y las similitudes con la historia de Juan Cuello no son despreciables.

Así y todo, Irene no es un gaucho enamoradizo que se involucra en un sinnúmero de pendencias, sino todo lo contrario; como Pablo Guevara, quiere vivir libremente, amar a una sola mujer y andar a sus anchas por el desierto, cuidando de su familia y divirtiéndose con sus amigos. Por otro lado, las escenas de su vida entre los indígenas, que en Juan Cuello de Gutiérrez tienen una distribución significativa, están sólo referidas por el narrador, cuando comenta las buenas relaciones que tenía el gaucho con el cacique Catriel, a quien había salvado la vida (Vedia, 1868: 61).

Las novelas de Vedia y Mansilla subrayan que el gaucho es consecuencia de un ambiente y de un sistema jurídico, político y social que no funciona. Pablo... se sitúa en la época de la Organización Nacional (posiblemente, durante el gobierno de Sarmiento), mientras que Aventuras... transcurre en los albores del rosismo y las dos obras acusan a sus respectivos gobiernos de ser responsables de la situación anómala de la campaña.

Para los liberales y unitarios, el gaucho representaba la barbarie de las provincias que había contaminado la ciudad a través de la tiranía de Rosas, ya que su cultura había sido asumida, fomentada y utilizada por el Restaurador. Pero las costumbres de esta vida rural y errante causaron, a la vez, un atractivo indiscutible entre los mismos que las rechazaban. De hecho, los que veían en el gaucho una amenaza a la cultura europea, hicieron las pinturas más perdurables de este tipo rioplatense. Esta 
idealización, iniciada sobre todo por Sarmiento, responde, sin duda, al discurso romántico occidental, en el cual el tipo humano característico de cada pueblo fue exaltado como símbolo nacional, al margen de la aceptación social de su encarnación real.

Si la idealización del gaucho llegó a su cénit en el discurso canonizador de Leopoldo Lugones de 1913, el tipo del gaucho desplazado a la ciudad, el compadrito, también fue reconocido en el siglo XX como personaje simbólico. Como el gaucho matrero, las acciones delincuentes del compadrito son justificadas por un pasado adverso, por la falta de educación, por los condicionamientos espacio-culturales o, simplemente, por la mala fortuna: todos estos, argumentos de su vida marginal. Como sucede con famosos bandoleros norteamericanos, el criminal heroico que "es llevado a una vida de delito por una injusticia o por cometer un acto que el estado, pero no la comunidad, considera criminal" (Ludmer, 1988: 233), se vuelve representativo, ya de la cultura ciudadana, ya de la rural. Pero, a diferencia del compadrito, las acciones violentas del gaucho, al menos en sus representaciones literarias, parecieron tener más justificativos ${ }^{4}$.

Los gauchos siempre fueron señalados como habitantes desfavorecidos por la sociedad y el gobierno y, además, esa marginalidad estuvo casi siempre vinculada con la delincuencia. A partir de Pablo... y Aventuras ... y, por supuesto, también en Martín Fierro (sobre todo, en la Ida), comenzó a funcionar un mecanismo de justificación de las acciones delictivas del gaucho que no impidió, sino que incluso fomentó la canonización de este personaje. De todos modos, la figura exaltada "oficialmente" no fue la de Juan Moreira ni Santos Vega ni Juan Cuello, sino Martín Fierro en su Vuelta: un gaucho pacífico, sabio, noble consejero y que, después de superar un pasado de desertor y pendenciero, se reforma.

El gaucho es considerado en todos estos textos como un producto de su entorno o, mejor aún, de la naturaleza extensa, solitaria e indomable del desierto. Esta afirmación tiene su origen, sin duda, en Facundo y Amalia de José Mármol. Asimismo, es uno de los puntos que recogen las dos novelas: la relación proporcional entre la desolación del paisaje y el modo de ser del gaucho.

En primer lugar, para Sarmiento no sólo la inmensidad es un obstáculo sino también las múltiples inquietudes que conlleva la vida en la pampa. Estas condiciones generan una inseguridad ambiental que templa el carácter del hombre, y relativizan la vida y la muerte (Sarmiento, 1990: 57). Una idea similar es recogida por Mármol en Amalia, pero en la descripción del gaucho que el narrador hace las condiciones climatológicas y geográficas se suman a la soledad total del individuo en su ambiente (Mármol, 2000: 575).

${ }^{4}$ Ver el trabajo de Josefina Ludmer (1999) sobre las representaciones del delito en la literatura argentina. Sobre todo, la lectura que hace sobre Juan Moreira y su serie de relaciones textuales. 
Sarmiento (1990) también alude al carácter moral del paisano que "se resiente de su hábito de triunfar de los obstáculos y del poder de la naturaleza: es fuerte, altivo, enérgico" (74), pero, aun así, para el sanjuanino estas características tienen menos relevancia que el peso de la libertad y la autonomía, valores también comentados por Mármol. Para Lucio V. Mansilla, por su parte, el gaucho no sólo es un producto autóctono, favorecido por las condiciones de la tierra y desprotegido por el gobierno, sino que también es lo más propio y, a la vez, lo más despreciado por los rioplatenses (Mansilla, 1947: 157).

Como se sostiene en Pablo..., el gobierno, además de abandonar al sujeto, restringe con su autoridad el valor más sagrado del gaucho: la libertad. Para un paisano como Pablo "la palabra soldado [es] como el zumbido de un enjambre de insectos dañinos. ¡Ay! Para el gaucho, tan amante, tan orgulloso de su libertad de acción, soldado significa prisionero para toda la vida" (Mansilla, 2007: 111-112).

Desde el momento en que el servicio militar es una limitación de su proceder, la patria, que para un criollo siempre fue un valor primordial, aunque entendida como "pago chico", se convierte en un proyecto ajeno y un tema de los puebleros. Pablo Guevara así lo considera, una vez que es enrolado a la fuerza por los policías, a pesar de haberles mostrado la papeleta de excepción que le habían dado por ser el único hijo vivo de madre viuda:

- Me hablan de la patria, añadió con amargura, ¿qué tengo yo que hacer con su patria y con su libertad? Yo también amo la libertad... mi libertad... ¿por qué me privan de ella?... ¿Por qué me arrancan de los pagos de mi madre, de los que amo?... ¡No!..., ya no creo en sus falsas palabras. Unitarios y federales, todos son iguales. Yo los aborrezco a todos, como ellos nos aborrecen a nosotros, pobres gauchos... (Mansilla, 2007: 165)

Para Pablo, los partidos políticos no significan nada ya que ninguno respeta su modo de vida. Más aún el estado se contradice, porque sus funcionaros no consideran el documento que ellos mismos le habían dado como prueba de identidad y excepción. Por otro lado, aquel sistema de conscripción estaba basado en una ley, aprobada en diciembre de 1823, por la cual todo ciudadano adulto de sexo masculino estaba obligado al servicio militar. Esta ley, vigente hasta finales del siglo XIX, fue aplicada en casi todas las provincias pero, dadas sus duras condiciones, tuvo siempre mala prensa y fue violada con frecuencia. La leva forzosa obligaba a casi todos los peones a cumplir con el servicio militar, con lo cual hubo durante años una gran carencia de trabajadores en los campos, ya que los que no aceptaban ser enrolados se escapaban hacia la frontera o a otras provincias libres de tal legislación. Dadas las constantes guerras y la necesidad perentoria de hombres, las autoridades muchas veces se saltaban los pasos habituales del procedimiento, por ejemplo, el juicio ceremonial del juez de paz (Slatta, 1985: 226). El nivel de coacción de la leva se acentuó a partir de un decreto de 1853, por el cual 
los militares podían entrar a las casas y propiedades y enrolar por dos años a los varones no enlistados en una unidad local (226).

Así, el aspecto de la partida adelanta lo que luego el narrador subrayará como una contraposición latente: en la ciudad, la autoridad "quiere decir casi siempre civilización, superioridad, refinamiento, cultura y teorías políticas" (105), pero en el campo, esa misma autoridad se convierte en brutalidad y fuerza, únicas leyes posibles (105). También hay una contradicción habitual entre los que gobernaban ya que, en las dos novelas, quienes se erigen como defensores de la ley y representantes de la autoridad son los mismos que después avasallan la dignidad de los demás o la propiedad privada. Así, el Juez de Paz, que tiene a su cargo a Clara, intenta aprovecharse de ella y por eso la joven prefiere huir con Irene Campoamor, un gaucho matrero que no podía ofrecerle nada, antes que permanecer con su tutor (Vedia, 1868: 105-106). Para Irene, el juez es un "conservador del orden público que quería violarlo en su propia casa" (106), una persona que se deja llevar por sus pasiones y que actúa irracionalmente, tal como se refleja en su reacción al conocer el robo de Clara (81).

La anomalía que denuncia Aventuras... es que el vicario de la justicia, que debía ser equilibrado, actúa según sus enconos y apetencias personales. Esta corrupción del mejor era aún peor en la campaña, porque el juez o comisario se erigía como el único representante del gobierno allí, la cara humana de la instancia superior a la que el hombre de campo debía responder, y ante la que, no sin rebeldías, cedía esporádicamente (Mansilla, 2007: 103) .

Otro tanto sucede en Pablo... con la partida que se presenta en la estancia del Federal, Juan Correa, e instala su campamento sin pedir permiso a su dueño, sin solicitar una hospitalidad que, en todo caso, no hubiera sido negada. La partida rompe con los códigos de cortesía del gauchaje, y hace uso de la estancia como si se tratase de un botín de guerra, "una especie de plaza conquistada, o mejor dicho, de propiedad usurpada" (Mansilla, 2007: 113). También en Aventuras..., la tropa llega al rancho de los Campoamor buscando a Irene, y su madre, con resignación, deja a los policías registrar la casa (Vedia, 1868: 56).

Diana Campoamor actúa como si estuviese acostumbrada a este tipo de registros $\mathrm{y}$, a pesar de sentirse agraviada, se atreve a desafiar a los militares. Ella sabe que su hijo se ha escapado y la partida no pierde tiempo en amenazarla ni obligarla a confesar, porque los gauchos huían siempre sin decir a dónde iban. Hay una victoria personal en las palabras resignadas y en la actitud retadora de Diana, pero al narrador no le es suficiente la descripción de la escena y encadena una serie de

${ }^{5}$ Esta necesidad del «bárbaro» por ponerle cara a la autoridad aparece también en la excursión de Mansilla, cuando el cacique Mariano Rosas le pregunta por el presidente y su nombre, y por el congreso o la constitución y su nombre, asimilando que detrás de cada estructura gubernamental había una sola persona (Mansilla, 1947: 213-214). 
preguntas sobre la incoherencia que implican este tipo de escenas: “Cómo es que un funcionario encargado de velar por la ejecución de las prescripciones de la ley se permite violar su espíritu? ¿Es posible castigar al infractor cuando se da el ejemplo de la infracción, o cuando se imita su procedimiento?" (Vedia 1868: 56).

En Pablo..., por otro lado, se sostiene que la debilidad de la autoridad y la extensión y poco dominio del territorio impiden que las leyes contra el crimen sean eficaces. Las leyes efectivas en Estados Unidos, sobre todo la dura Lynch-Law, son inaplicables en el país, debido a los usos y costumbres de la campaña (Mansilla, 2007: 278).

Si bien Pablo e Irene comparten con la mayoría de los gauchos, literarios y legendarios, la condición de individuos perseguidos por la ley, no son delincuentes de la misma naturaleza. Ninguno de ellos dos, tampoco el Juan Moreira ni el Pastor Luna de Eduardo Gutiérrez, siguen la estela criminal de Santos Vega, ni la de Juan Cuello, ni el bandolerismo de los hermanos Barrientos (Laera, 2003: 209).

A pesar de que su historia se inspiró en la de Cuello, Irene no tiene un prontuario de muertes caprichosas. Tanto él como Pablo cometen delitos menores: enfrentarse a la policía en una pulpería, "secuestrar" a Clara y evitar el enrolamiento, por parte de Campoamor; y escaparse de la tropa militar y asociarse a un peligroso matrero, Guevara. Aunque Irene ostenta maneras más desafiantes ante la autoridad, tanto él como el protagonista de Pablo... sólo quieren vivir libres y tranquilos, sin dar cuenta a nadie de su estilo de vida nómade y autónomo. Pablo, como Martín Fierro, acepta la orden militar casi apáticamente pero luego la evade, mientras que Irene no tiene reparos en anunciar su presencia a grandes voces en la pulpería, a sabiendas de que la policía podía presentarse, y deja a tres milicianos fuera de combate una vez que éstos aparecen para encarcelarlo (Vedia, 1868: 12-13).

Pablo e Irene representan a una clase amplia, inculta y resistente; no tienen más ley que la propia y la dinámica de la organización estatal resulta un escollo en sus vidas. Pero no se unen a bandas de ladrones ni buscan perjudicar el orden público a toda costa, aunque a veces justifican sus acciones de acuerdo a su propio criterio. Es así como, desde el momento en que rechazan la leva o desertan, la dialéctica legislativa los coloca, aún más si cabe, del lado de la marginación. La misma ley que pone orden, convierte a dos gauchos honestos e inofensivos en seres exclusivamente útiles para la guerra y la defensa de la frontera. Aunque la carta magna los declare ciudadanos argentinos, la actitud de la autoridad que aplica aquella ley contradice sus intenciones (Laera, 2003: 321).

Tanto Pablo... como Aventuras... coinciden en que el gaucho tiene un germen de bien que sería realizable "si fuesen bien dirigidas sus tendencias" (Vedia, 1868: 14). Esta predisposición a la bondad (51) y a la docilidad forma parte, para Vedia, de la primera naturaleza del gaucho, aunque es desaprovechada y maltratada por el gobierno (34). Esa primera naturaleza, además, tiene un principio de activismo que lleva al individuo a buscar aventuras y lugares nuevos en los que medir sus destrezas (Vedia, 1868: 63). 
Sin embargo, por sobre la primera naturaleza del gaucho "caracterizada por sus "nobles instintos"” (Laera, 2003: 302), emerge una "segunda naturaleza", al decir de Gutiérrez (1888: 117): "la instancia en que la pasión violenta se degrada: la segunda naturaleza, la viciosa, se opone a la primera y paulatinamente ocupa su lugar" (Laera, 2003: 302). El inicio de la pendiente del crimen es éste: "a medida que el genio del mal penetra en él, siéntese con energías increíbles, con un valor a toda prueba" (Mansilla, 2007: 113). Esa nueva condición, sobrepuesta a las virtudes innatas del gaucho, que luego serán exaltadas como valores, es causada por las altas esferas (Vedia, 1868: 19).

Lo que queda expreso, así, es que el gaucho tiene una tendencia que lo arrastra, tarde o temprano, hacia los márgenes de la legalidad. Este aspecto de la personalidad del paisano responde a su carácter indomable y violento, que reacciona cuando se comete alguna injusticia. El desenvolvimiento de las pasiones más auténticas es lo que, finalmente, fundamenta las acciones que hacen de él un héroe popular, y no un delincuente.

Esta explicación de la doble naturaleza del gaucho justifica, tanto en Aventuras... como en Pablo..., la existencia del que Sarmiento tipificó como "gaucho malo", concepto que los dos romances recogen 6 . Un "gaucho malo", en

6 Sarmiento compara este tipo, a su vez, con el hawkeye o trapper de Cooper. Reproduzco la famosa tipificación de Sarmiento: "Llámanle el gaucho malo, sin que este epíteto lo desfavorezca del todo. La justicia lo persigue desde muchos años; su nombre es temido, pronunciado en voz baja, pero sin odio y casi con respeto. Es un personaje misterioso; mora en la Pampa; son su albergue los cardales; vive de perdices y mulitas; y si alguna vez quiere regalarse con una lengua, enlaza una vaca, la voltea solo, la mata, saca su bocado predilecto, y abandona lo demás a las aves mortecinas. De repente se presenta el Gaucho Malo en un pago de donde la partida acaba de salir; conversa pacíficamente con los buenos gauchos, que lo rodean y admiran; se provee de los vicios, y si divisa la partida, monta tranquilamente en su caballo, y lo apunta hacia el desierto, sin prisa, sin aparato, desdeñando volver la cabeza. La partida rara vez lo sigue; mataría inútilmente sus caballos; porque el que monta el Gaucho Malo es un parejero pangaré tan célebre como su amo. Si el acaso lo echa alguna vez de improviso entre las garras de la justicia, acomete a lo más espeso de la partida, y a merced de cuatro tajadas que con su cuchillo ha abierto en la cara o en el cuerpo de los soldados, se hace paso por entre ellos; y tendiéndose sobre el lomo del caballo para sustraerse a la acción de las balas que lo persiguen, endilga hacia el desierto, hasta que poniendo espacio conveniente entre él y sus perseguidores, refrena su trotón y marcha tranquilamente. Los poetas de los alrededores agregan esta nueva hazaña a la biografía del héroe del desierto, y su nombradía vuela por toda la vasta campaña. A veces se presenta a la puerta de un baile campestre con una muchacha que ha robado, entra en baile con su pareja, confúndese en las mudanzas del cielito, y desaparece sin que nadie se aperciba de ello. Otro día se presenta en la casa de la familia ofendida, hace descender de la grupa a la niña que ha seducido, y desdeñando las maldiciones de los padres que lo siguen, se encamina tranquilo a su morada sin límites. Este hombre divorciado con la sociedad, 
suma, es aquel que participa de sucesos violentos, que se enfrenta con descaro a la autoridad militar y que siempre logra escaparse. Además, sus acciones están recubiertas siempre de audacia e indolencia. El gaucho de esta especie suele hacer todo a su gusto y desafía siempre los límites impuestos, y así es envuelto en un halo de leyenda.

En estos relatos el "gaucho malo" es el portavoz autorizado para acusar la arbitrariedad de la ley. Porque, aunque es consciente de sus malas acciones, cometidas bajo el efecto de su naturaleza violenta ${ }^{7}$, tiene claro que el problema es la incompatibilidad de las instituciones con su estilo de vida. La constitución y el estado no comprenden su modus vivendi $\mathrm{y}$, a causa de esto, son juzgados duramente (Mansilla, 2007: 202-203).

$\mathrm{Y}$ si este personaje, el matrero imposible de apresar, se autodefine como defensor del pueblo, la masa campesina lo elige como su representante y lo protege. La instauración como héroe de los paisanos se genera por la transmisión oral de su historia y, de este modo, sus simples disputas se convierten en grandes hazañas. Así, Irene Campoamor recupera una yeguada, botín de un malón de los indios chehueches y, a los pocos días, el relato atraviesa la campaña (Vedia, 1868: 131). Hace otro tanto con la propiedad del estado, de la que dispone a su antojo "a título de represalias" (184), sin que su fama disminuya. Irene tiene una habilidad especial para recorrer pueblos sin ser visto y, en los momentos de mayor peligro, se pasa al desierto. Estas acciones son consideradas como muestras de valentía y heroísmo para sus congéneres (Vedia, 1868: 61). Pero la relación entre popularidad y criminalidad es inversamente proporcional en el relato, porque cuanto más persiguen al matrero, más conocido y admirado es por su entorno (Vedia, 1868: 131).

A partir de su huida, la fama de Pablo también crece pero, en este caso, no por sus aventuras sino porque se convierte en una víctima para la opinión pública. Micaela, su madre, viaja a Buenos Aires para reclamar al gobernador la infracción cometida por la partida al enrolar a su único hijo. En la puerta de la gobernación, Micaela Guevara se encuentra con un guardia nacional que, conmovido por su historia, promete hacer campaña a favor de Pablo desde su columna de La Tribuna. El militar pergeña en su mente los artículos contra "los abusos de la autoridad

proscripto por las leyes; este salvaje de color blanco no es en el fondo un ser más depravado que los que habitan las poblaciones. El osado prófugo que acomete una partida entera, es inofensivo para los viajeros: el Gaucho Malo no es un bandido, no es un salteador" (Sarmiento, 1990: 88-89).

7 También un «gaucho malo» es capaz de dominar sus tendencias bajas, como lo demuestra Caramurú, al ver que puede aprovecharse de Lía en la soledad del desierto; sin embargo, recurre a su fuerza de voluntad para no dejarse "arrebatar por su primer impulso. Acción sobrehumana en el gaucho, y mucho más en el montonero" (Magariños Cervantes, 1865: 65). 
militar en la campaña" (Mansilla, 2007: 249). Así, los artículos del guardia nacional ponen el tema de la defensa del gaucho en boca de los mismos milicianos. El comandante Vidal no sólo defiende a Pablo por conocer a su familia y saber de la injusticia perpetrada; también se preocupa por todos aquellos paisanos inocentes que ven que la única forma de sobrevivir es convertirse en un "gaucho malo":

Con el sistema del terror, de la opresión y de la arbitrariedad, todos se volverán gauchos malos en seis meses, si nosotros no ponemos remedio a la cosa. Créame usted coronel, en ese punto los federales son más hábiles que nosotros. Los gauchos lo saben, y de ahí por qué no nos quieren. (Mansilla, 2007: 292)

Si para Ludmer (1988: 16) la ilegalidad es un límite del género gauchesco porque ahí se enfrentan las leyes escritas de la ciudad y las no escritas de la comunidad rural—, la leyenda oral anticipa al texto literario, desde la difusión de la vida del matrero, contada de boca en boca en Aventuras..., hasta la lectura masiva de las crónicas sobre Pablo en Buenos Aires ${ }^{8}$. Así, la marginación in crescendo del gaucho proscrito y la filiación de los paisanos señalan el comienzo de la conformación del héroe popular. Un héroe que es gaucho malo o paisano inadvertido, pero que se erige en el imaginario público como una víctima de la autoridad de la ciudad.

De la misma manera, y en consonancia con la dialéctica de la cadena de usos que Ludmer propone, el gaucho matrero es considerado en primer lugar, un individuo fuera de la ley; luego, un paladín popular de la campaña y víctima del sistema y la sociedad; y finalmente, con Martín Fierro y Juan Moreira, un héroe literario. En esta línea de evolución se inscriben tanto Irene Campoamor como Pablo Guevara. Pero la propuesta de estas dos novelas no acaba ahí, sino que la construcción de un modelo cultural del gaucho como verdadero prototipo nacional debe completarse, según estos romances, con un proyecto educativo para aquél; idea que también se deduce de las obras canónicas del período.

Aquel gaucho proscrito cuya vida, convertida en una leyenda oral, era admirada por los habitantes de la campaña y ganaba cada vez más adeptos, tuvo una continuidad en dos fenómenos literarios extraordinarios de la Organización Nacional: la difusión, a través de la lectura en voz alta en ranchos y pulperías, del Martín Fierro y la multiplicación de suscripciones de El Nacional, gracias a los folletines de gauchos de Gutiérrez. Estos acontecimientos de la literatura masiva fueron muy importantes en su época, aunque hoy por hoy haya muy pocos estudios que registren esta particular relación entre la literatura y las leyendas populares

${ }^{8}$ La dinámica de las crónicas de La Tribuna sobre Pablo remiten (por supuesto, sin buscarlo) al éxito de lectura de folletines de gauchos de Eduardo Gutiérrez, que también empezaron como crónicas policiales. 
durante el siglo XIX. La exaltación de la figura del gaucho, además, se suele asociar directamente con el afán simbólico del primer centenario de la revolución de mayo, pero es interesante ver que la identificación popular con el campesino comenzó mucho antes de la canonización de la obra de Hernández.

En el comienzo de Facundo, Sarmiento vislumbra que el mundo rural y sus personajes llegarían a ser distintivos de la nacionalidad y, en especial, de la literatura argentina (Sarmiento, 1990: 81-82). Esta acertada sentencia, curiosa por la contradicción con su ideal civilizador, no se cumpliría del todo hasta las últimas décadas del siglo XIX, pero comenzaría a aparecer en las novelas de Mansilla y Vedia y en otras obras del período. En ellas, la idealización del gaucho se produce a través de dos recursos narrativos: la prosopografía, o descripción del aspecto exterior del paisano, y la etopeya, la enumeración de las características de su personalidad.

A la vez que esta descripción presenta al personaje principal como atractivo, recurso que busca una aceptación inmediata del lectorado urbano, el enfoque tan exhaustivo de la indumentaria del paisano tiene como objetivo, a mi entender, desvincularla de lo improvisado y lo ruin y convertirla en elemento distintivo, símbolo de una rusticidad elegante?.

Por su parte, en estas dos novelas, la etopeya de los gauchos se relaciona con sus estructuras narrativas (en las que predominan el peregrinaje y las aventuras), porque en los hechos que marcan sus vidas se ponen a prueba el carácter y la valía de los protagonistas. Aunque las destrezas con el cuchillo y el caballo siembran los dos textos, y definen la valentía como característica distintiva del paisano, la idealización del gaucho se produce en ellos por la exaltación de otros valores, como la hospitalidad y la amistad (Vedia, 1868: 24; Mansilla, 2007: 130). Sin identificar virtud con hábito, sino definiéndola como disposición anímica, el dar techo y comida a un forastero era considerado una acción natural de la vida en la pampa.

Por otro lado, la tendencia al discurso consiliario en las novelas de gauchos se relaciona con la estructura de relato de iniciación: existen autoridades que preceden al paisano en la vida y esas tienen el poder de transmitir su sabiduría y su forma de hacer las cosas. Esta función de la amistad aparece en las charlas de Irene y Santos en Aventuras..., y también en los consejos de Anacleto a Pablo en Pablo... (Mansilla, 2007: 253-254), así como, ya en una actitud paternal, en las sentencias del viejo Vizcacha y las palabras de Fierro a sus hijos.

En suma, ajenas a la función que cobraría en los inicios del siglo XX la figura idealizada del gaucho, las novelas de Vedia y Mansilla, como otros textos aludidos, son sugerentes lecturas que anteceden una temática (la defensa del gaucho como

${ }^{9}$ En contraposición a su figura, su pareja de aventuras, el gaucho malo Anacleto, "como los otros gauchos, lleva chiripá y calzoncillos flotantes, pero todo sucio, arrugado y roto en una porción de partes" (Mansilla, 2007: 200). 
víctima del estado), y un proceso (la instauración del símbolo de identidad nacional). Las dos vienen a decir que, si bien la falta de instituciones en el desierto es el origen de individuos ignorantes, huérfanos e infieles, tampoco la educación es la garantía de que los hombres sean civilizados. Por el contrario, más que la escuela y la iglesia, la autoridad materna, como referencia social natural frente a la carencia de estructuras de civilización, es la que genera el tipo virtuoso del gaucho; el mismo que, mediante el discurso criollista, pasará de ser un paria social a un auténtico ciudadano argentino.

\section{BIBLIOGRAFÍA}

BATTICUORE, Graciela.

2005 La mujer romántica. Lectoras, autoras y escritoras en la Argentina: 1830-1870. Buenos Aires: Edhasa.

CHUMBITA, Hugo.

2000 "Juan Cuello y sus biógrafos", Todo es Historia, mayo, n 394, pp. 28-36.

GUTIÉRREZ, Eduardo.

1888 Juan Moreira. Buenos Aires: N. Tomassi.

LAERA, Alejandra.

2003 "Géneros, tradiciones e ideologías literarias en la Organización

Nacional", en Noé Jitrik (dir), Historia crítica de la literatura argentina. La lucha de los lenguajes, Julio Schvartzman (dir. vol.), vol. II. Buenos Aires: Emecé, pp. 407-437.

LUDMER, Josefina.

1988 El género gauchesco. Un tratado sobre la patria. Buenos Aires: Sudamericana.

1999 El cuerpo del delito. Un manual. Buenos Aires: Perfil.

MAGARIÑOS CERVANTES, Alejandro.

1865 Caramurú. La vida por un capricho. Buenos Aires: Todomiro Real y Prado.

MANSILLA, Eduarda.

2007 Pablo, o la vida en las pampas. Lucio V. Mansilla (trad.). Buenos Aires: Colihue/Biblioteca Nacional.

MANSILLA, Lucio V.

1947 Una excursión a los indios ranqueles. México: Fondo de Cultura Económica.

MÁRMOL, José.

2000 Amalia. Madrid: Cátedra. 
MASIELLO, Francine.

1997 Entre civilización y barbarie: mujeres, nación y cultura literaria en la Argentina moderna. Rosario: Beatriz Viterbo.

MIZRAJE, María Gabriela.

2007 "E.M.G y la representación cultural (Nuevos mapas textuales, nuevos géneros)", en Eduarda Mansilla, Pablo, o la vida en las pampas. Buenos Aires: Colihue/Biblioteca Nacional, pp. 21-84.

ORTIZ GAMBETTA, Eugenia.

2013 Modelos de civilización en la novela de la Organización Nacional (1850-1880). Buenos Aires: Corregidor.

SARMIENTO, Domingo F.

1990 Facundo. Civilización y Barbarie, Roberto Yahni (ed.). Madrid: Cátedra.

SCHLICKERS, Sabine.

2007 "Que yo también soy pueta". La literatura gauchesca rioplatense y brasileña (siglos XIX-XX). Madrid/Frankfurt: Iberoamericana/ Vervuert.

SLATTA, Richard.

1985 Los gauchos y el ocaso de la frontera. Rafael Urbino (trad.). Buenos Aires: Sudamericana.

VEDIA, José J. de.

1868 Aventuras de un centauro de la América Meridional. Buenos Aires: Imprenta del Orden.

WILLIAMS ÁLZAGA, Enrique.

1955 La pampa en la novela argentina. Buenos Aires: Estrada. 